\title{
Acapulco, \\ de destino turístico \\ a una ciudad de riesgo
}

\section{DULCE MARÍA QUINTERO ROMERO*}

En menos de cuatro décadas, luego de ser un destino turístico con reconocimiento internacional que ofrecía descanso, tranquilidad y diversión, Acapulco se convirtió en la tercera ciudad más violenta de Latinoamérica, ${ }^{1}$ donde lugareños y visitantes son amenazados. Si bien se maneja una explicación muy general, en la que se ubica la violencia como consecuencia de la lucha contra el narcotráfico y la disputa territorial de grupos delincuenciales, aquí se estudiará la complejidad del fenómeno con fundamento en que la producción de riqueza en este contexto ha originado una creciente situación de riesgo, la cual se agudiza de manera diferenciada en los sectores económicos y con mayor crudeza en los más pobres.

\section{Introducción}

Para muchos acapulqueños el problema comenzó con el enfrentamiento el 27 de enero de 2006 en una popular colonia a la luz del día. Desde tiempo atrás, la consolidación de Acapulco como centro turístico y competitivo ha generado acciones que buscan mejores ganancias y que hoy se ligan a esta situación de riesgo, tal como lo relata Juan Alberto Cedillo, corresponsal de la Agencia EFE, en La cosa nostra en México (1938-1950), libro basado en archivos clasificados del FBI docu-

investigadora de la Unidad de Gestión del Desarrollo,

Universidad

Autónoma de

Guerrero menta la presencia de la mafia italiana que,

${ }^{1}$ «The world's most violent cities», The Economist, 3 de febrero de 2016, http://www.economist.com/blogs/graphicdetail/ 2016/02/daily-chart-3 asociada a políticos y empresarios de México, ocupó el puerto como centro de operaciones para el comercio de la droga durante muchos años.

El gobierno alemanista marcó el sentido del progreso económico, por lo que el turismo se volvió una prioridad para Guerrero, hecho que desencadenó la entrada masiva de capital estadounidense, el fortalecimiento de la burguesía gobernante, la corrupción administrativa y la realización creciente de negocios particulares subsidiados por el Estado. ${ }^{2}$

\footnotetext{
2 Ernesto Valenzuela Valdivieso y Atlántida Coll-Hurtado, «La construcción y evolución del espacio turístico de Acapulco (México)», Anales de Geografía, vol. 30, núm. 1, julio de 2010, pp. 163-190, http://revistas.ucm.es/index.php/ AGUC/article/view/31893
} 
El proyecto turístico promovió la formación de grupos empresariales (locales-nacionales), de manera que facilitó la apropiación del espacio, privilegió la dotación de infraestructura urbana, la construcción de caminos, entre otros, hasta conseguir la integración de una ciudad segmentada donde se presenta la profundización de las desigualdades espaciales conforme a sus grupos de ingreso. ${ }^{3}$

Los promotores del progreso y la modernidad que confiaron en el turismo en Guerrero han orientado el modelo de desarrollo desde hace varios años hacia sus intereses económicos en el corto plazo en detrimento de decisiones del bienestar general. En ese sentido, los costos son muy elevados para la calidad de vida de miles de familias que viven en las colonias populares sumidas en una «violencia estructural» ${ }^{4}$ en un ambiente de injusticia, pobreza, sufrimiento y muerte.

Acapulco, una ciudad segmentada donde se presenta la profundización de las desigualdades espaciales conforme a sus grupos de ingreso.
${ }^{3}$ Guadalupe Margarita González Hernández, «Segregación socioespacial en Acapulco (1990-2000)», en América Rodríguez, José Luis Rosas, Dulce Quintero y Manuel Ruz (coords.), Los retos del desarrollo en Acapulco, Acapulco, Unidad de Ciencias de Desarrollo Regional-Universidad Autónoma de Guerrero, 2009, pp. 57-74.

${ }^{4}$ El término propuesto por Johan Galtung y retomado en Itziar Larizgoitia, «La violencia también es un problema de salud pública», Gaceta Sanitaria, vol. 20, supl. 1, 2006, p. 68.
Aliados con los representantes de los gobiernos estatal y local, los «turisteros» propiciaron una alta permisividad en el desarrollo de esta actividad (todo en favor de la diversión de los visitantes); ignoraron, minimizaron y satanizaron los procesos de conflictividad social (guerrilla y reclamos sociales) ${ }^{5}$ que pusieran en duda la efectividad de su modelo. No obstante, dejaron fuera de sus prioridades a las zonas del territorio estatal que no encajaron en su proyecto; ello permite dilucidar que el rezago social del territorio guerrerense facilitó la producción de estupefacientes hasta convertirse en 2015 en la principal productora de goma de opio, según datos de la Secretaría de la Defensa Nacional. ${ }^{6}$

Hoy, Acapulco enfrenta una situación de violencia concebida como un problema de seguridad, la prioridad es evitar afectaciones a la actividad turística, sin considerar los costos actuales y futuros para los habitantes de la ciudad. Por tanto, es imprescindible discutir costos sociales de esta producción de ganancias de la «industria sin chimeneas»y la generación de riesgos, donde las desigualdades sociales y la segregación propician

${ }^{5}$ Dulce María Quintero Romero, José Francisco Ruiz Massieu y los periodistas en Guerrero, Gobierno del Estado de Guerrero, 2000.

${ }^{6}$ Javier Trujillo, «Guerrero, entre los principales productores de amapola: ejército», Milenio, 5 de septiembre de 2015, http://www.milenio.com/policia/amapola_Guerrero -produccion_amapola_Guerrero-region_militar_Guerrero _0_586141549.html

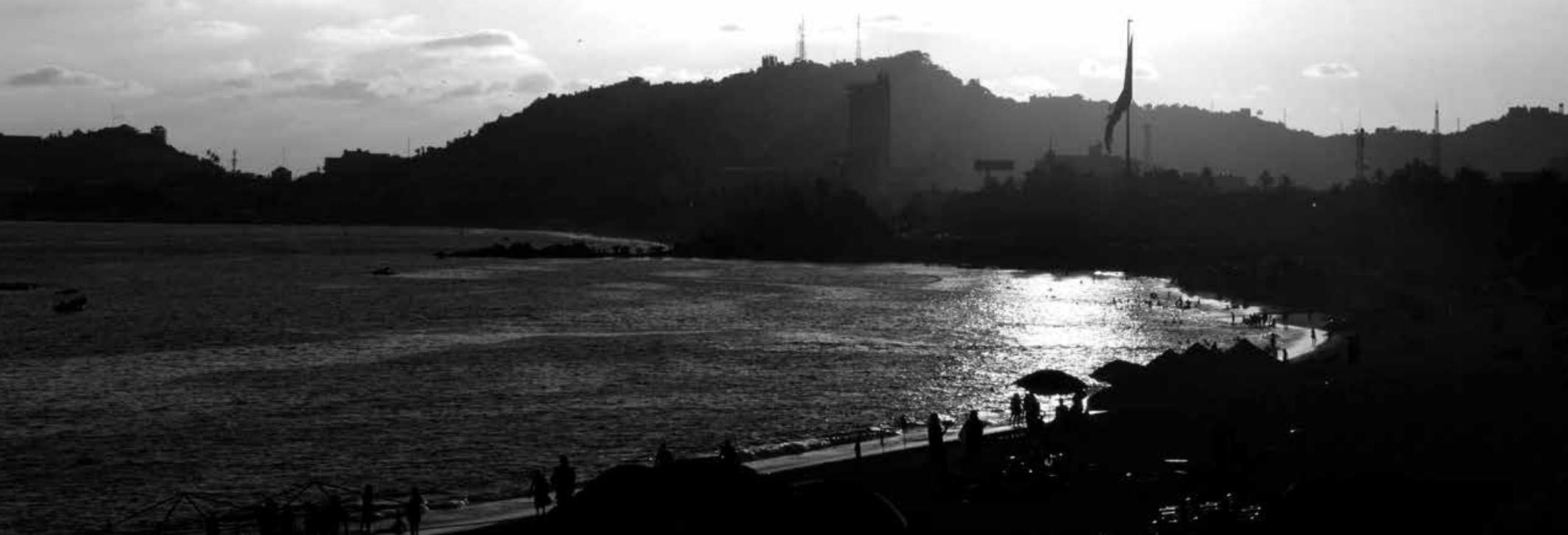



cotidianeidad de los más pobres, aquellos que viven en zonas marginales y para quienes cada paso les representa peligro.

\section{Sociedad de riesgo y violencia}

Beck sostiene que la producción social de la riqueza en las sociedades actuales conlleva a una creciente producción social de riesgo, cuyas consecuencias políticas y económicas deberían dirigir políticas gubernamentales para reducirlas. El autor aborda la expansión de los riesgos ambientales a partir de la globalización y los procesos de transformación económica, a fin de probar que la sociedad de riesgo se origina allí donde los sistemas normativos y las instituciones sociales fracasan cuando intentan conseguir la necesaria seguridad ante los peligros desencadenados por las decisiones emprendidas.

Esta propuesta posibilitará explicitar cómo una actividad generadora de ganancias a nivel mundial propicia situaciones de riesgo y convierte a las políticas gubernamentales en ineficaces al entretejer intereses políticos y económicos que los norman. De igual modo, puntualiza en la situación de violencia que vive hoy Acapulco, resultado de una serie de acciones efectuadas por empresarios y políticos ligados a la industria turística, quienes en la búsqueda de generar mayores ganancias desatendieron los procesos de segregación social en la que se expandió la producción y el comercio de drogas.

La propuesta de la sociedad de riesgo muestra cómo en este caso la vida, la seguridad de los ciudadanos y el disfrute de sus derechos humanos, son amenazados por los peligros desencadenados por el mercado del narcotráfico; también por la toma de decisiones re- que los hechos de violencia sean parte de la

mediales de los responsables de su seguridad, para quienes los intereses económicos son primordiales, y donde la lógica segregacionista antepone la inversión y subestima el origen de los hechos, los involucrados y más aún las víctimas.

Lo anterior explica la ausencia de políticas públicas. La violencia se muestra como un conteo de hechos presumiblemente transitorios desvinculados de la pobreza, la exclusión y las desigualdades sociales. ${ }^{7}$ No obstante, el mayor riesgo es ignorar el impacto intertemporal y la transmisión intrageneracional de la violencia; en opinión de Beck, las afectaciones de los riesgos se democratizarán entre las masas y un efecto boomerang alcanzará a todos.

Esto parece no tener relevancia, pues los riesgos adquieren un sentido de clase mientras sea posible «comprar» tranquilidad, de manera simbólica o material, o bien evitarlos. Son ricos (en ingresos, poder, educación) quienes pueden acceder a la seguridad y la libertad

${ }^{7}$ Itziar Larizgoitia, op. cit.

Acapulco enfrenta una situación de violencia concebida como un problema de seguridad, la prioridad es evitar afectaciones a la actividad turística, sin considerar los costos actuales y futuros para los habitantes de la ciudad. 


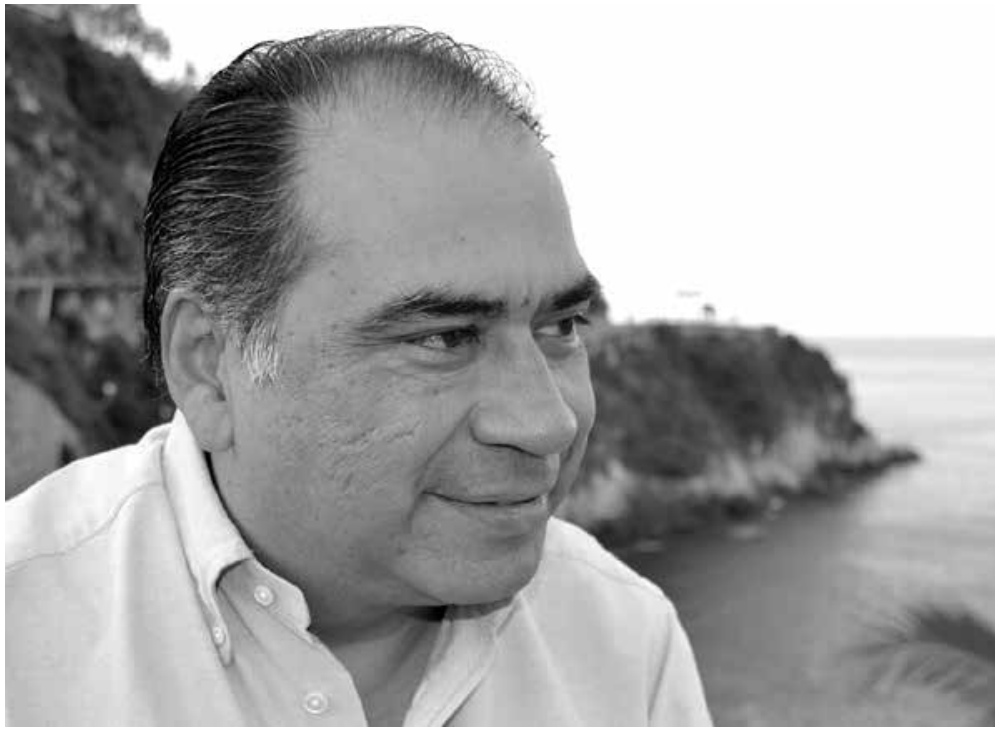

Héctor Astudillo

Flores, gobernador de Guerrero.

Fotografía: Sergio Flores Prensa

\section{Daños por violencia en Acapulco}

A diferencia de lo ocurrido en ciudades colombianas, las cuales enfrentan secuelas de violencia y el problema de la documentación es una prioridad, en Acapulco los datos recientes sobre enfrentamientos, extorsiones, secuestros, robos con violencia, muertos, heridos, negocios cerrados, contracción del mercado inmobiliario y otros son imprecisos y de difícil acceso. Para las instituciones gubernamentales significa un «aquí no pasa nada» en sintonía con el gobernador de Guerrero, Héctor Astudillo Flores, cuando en abril pasado planteó a los periodistas un «pacto de silencio» ante los hechos de violencia, luego exhortó a los políticos guerrerenses a «no lucrar con la violencia» en alusión a los reclamos de seguridad; en el caso de los ciudadanos de Zihuatanejo mostró una postura incisiva al prohibirles hablar de la inseguridad vivida para no alejar a los turistas. ${ }^{9}$

${ }^{8}$ Ulrich Beck, La sociedad del riesgo. Hacia una Nueva Modernidad, Barcelona, Paidós, 1986.

${ }^{9}$ Héctor Briseño, «Astudillo Flores pide a periodistas de Guerrero un pacto de silencio», La Jornada, 6 de abril de 2016,
Las únicas acciones de respuesta se orientan al fortalecimiento de operativos en materia de seguridad; sin embargo, todavía se cuestiona el asesinato de 38 personas en las vacaciones de Semana Santa, periodo en el que la ocupación hotelera fue de 92 por ciento, al tiempo que se desplegaron 4 mil 500 integrantes de las fuerzas de seguridad de los tres niveles de gobierno, incluyendo al Ejército y la Armada de México. ${ }^{10}$

Este hecho ha resultado muy costoso para la industria turística, pero no se compara con la realidad de los habitantes, en la que los operativos de seguridad son esporádicos o no llegan, pues la situación de riesgo no sólo se presenta en las solitarias calles nocturnas, sino que se hace latente a plena luz del día cuando las balaceras ocurren justo al momento de tomar un colectivo, viajar en un autobús urbano, comprar en el mercado o llegar a la escuela. El riesgo reside en el entorno de las actividades cotidianas, en una conversación acerca de muertos y levantados, o cuando se trata de un hecho que pasó cerca o afectó a un conocido, un vecino o un familiar.

Cada vez es más notoria la fragmentación de grupos delincuenciales y la expansión de la delincuencia común al enfrentar hechos de violencia no documentados como las prácticas de extorsión a pequeños negocios y locatarios de mercados o tianguis, la presencia de vigilantes (halcones) en las calles, el funcionamiento de «casas de seguridad» en colonias, el robo a transeúntes y todo aquello que no se denuncia por temor a represalias de parte de los grupos delincuenciales, en especial por la ineficacia, la corrupción de la policía y el sistema de justicia que generan un alto nivel de

p. 15, http://www.jornada.unam.mx/2016/04/06/politica/015 n2pol

${ }^{10}$ Rolando Aguilar, «Violencia imparable en Guerrero; asesinan a 38 personas en Acapulco», Excélsior, 27 de marzo 2016, http://www.excelsior.com.mx/nacional/2016/03/27/10 83100 


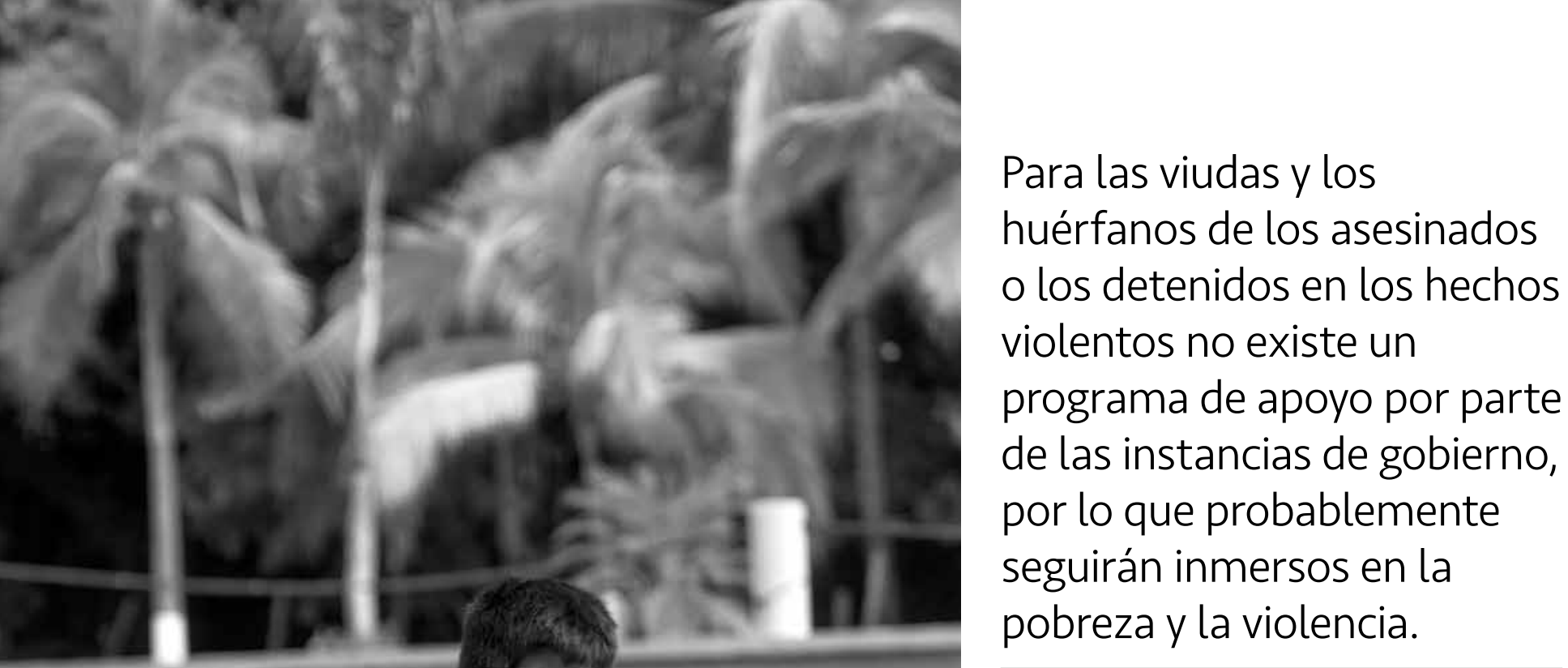

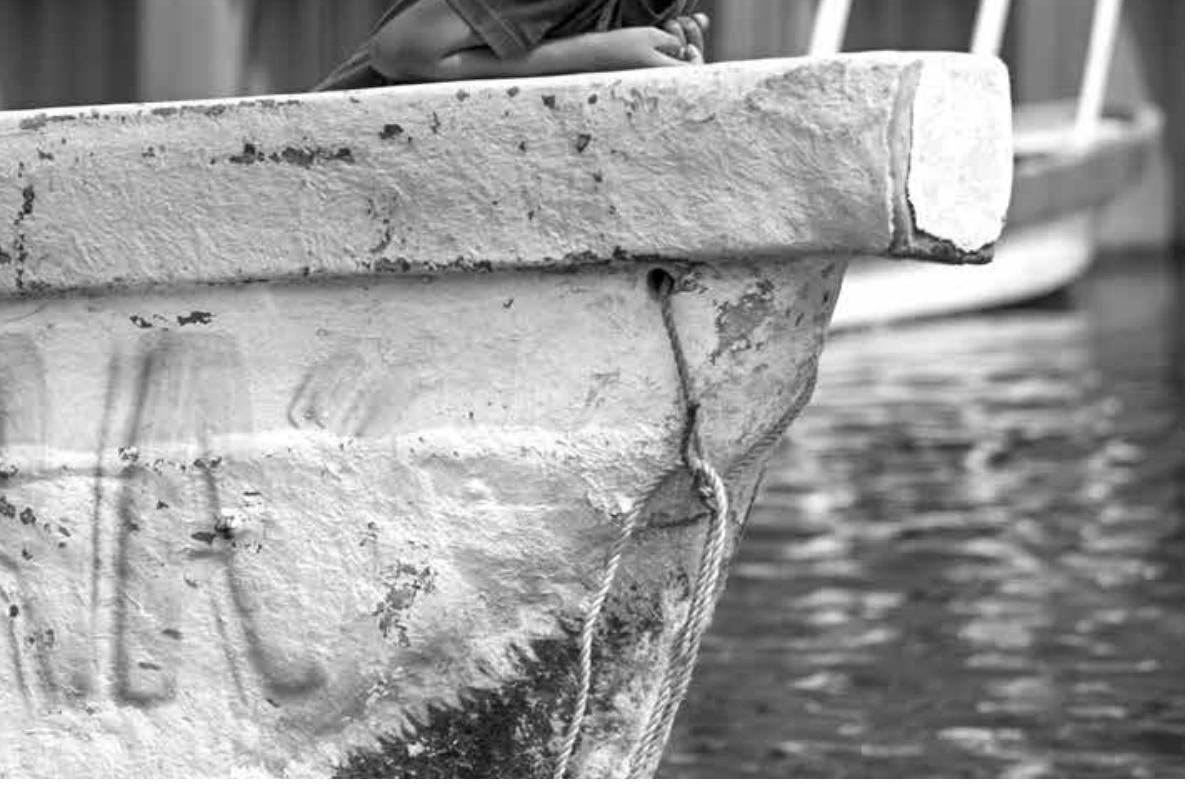

vecinos, así como mantener responsabilidades sociales y obligaciones, por tanto es indispensable recibir atención que permita evaluar y afrontar esos sucesos traumáticos y sus

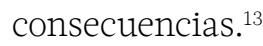

Los analistas del impacto económico y social de la violencia lo relacionan con la desesperanza, la desconexión cognitiva y el abuso de sustancias tóxicas. Advierten que el clima

${ }^{13}$ Alberto Concha, «Impacto social y económico de la violencia en las Américas», Biomédica, núm. 22, diciembre 2002, http://www.redalyc.org/articulo.oa?id=84309604 social dominado por el miedo, el odio y la ansiedad, el trauma psicosocial, la pérdida de autoestima, la desesperanza y la sensación de injusticia de las víctimas facilita la perpetuación de la violencia y su consecuente transformación en un problema a largo plazo.

A lo anterior debe agregarse el impacto que tiene en los afectados, los cambios en la cotidianeidad de la comunidad, el derecho a disfrutar, a convivir, a movilizarse, a hacer uso de los bienes públicos, los cuales cuando no se tienen, agudizan la desigualdad social, la pobreza, el nivel de desarrollo, la falta de oportunidades para la educación y el trabajo, el resquebrajamiento de valores como el respeto al derecho de los demás, mismo que daña los procesos de solidaridad y propicia mayor corrupción.

Respecto a los jóvenes, se percibe un futuro desalentador con expectativas de empleo limitadas, frente a ello se inquiere: ¿valió la pena correr el riesgo de salir de casa para acudir a la escuela? ${ }^{14}$ La conformación de un presente marcado por la violencia avisora un futuro desesperanzador. Como parte de la cotidianeidad, las familias observan la muerte, el abuso y

${ }^{14}$ Dulce María Quintero Romero, «Educación en derechos humanos en las universidades para enfrentar la violencia», RICSH Revista Iberoamericana de las Ciencias Sociales y Humanísticas, vol. 2, núm. 3, 2014, pp. 1-11. 
las agresiones. Complementariamente, se aprecia la reducción de recursos para el desarrollo social y económico a fin de atender la violencia; en el caso de Guerrero se estima un impacto económico per cápita de 36 mil 33 millones de pesos para la contención del fenómeno en 2015, esto lo ubica en el primer lugar en el destino de recursos a nivel nacional. ${ }^{15}$

Referente a las viudas y los huérfanos de los asesinados o los detenidos en los hechos violentos, no existe un programa de apoyo por parte de las instancias de gobierno. La iglesia católica, a través de la arquidiócesis de Acapulco, puso en marcha un programa de atención dirigido a las familias perjudicadas denominado Confesionarios para la violencia. En 2012 sumaban trescientas personas atendidas en los centros de escucha que operan en las colonias donde se registran altos índices delictivos.

El propósito de la iniciativa del párroco Jesús Mendoza es tratar familias completas golpeadas por la violencia, víctimas directas e indirectas de secuestros, asesinatos, extorsiones y desapariciones. Aparte de los religiosos participan psicólogos, abogados, tanatólogos y voluntarios. Aunque se brinda una ayuda espiritual, jurídica y psicológica, los avances son restringidos ante la magnitud del fenómeno.

\section{Posibles soluciones}

La violencia en Acapulco, derivada del narcotráfico, obliga a construir propuestas en un esfuerzo de integración de conceptos, metodologías y, probablemente, dinámicas y estilos de trabajo multidisciplinarios. Con la intención de desenmarañar el problema y sus consecuencias, es prioritario que se reconozca la situación de riesgo en que vive gran parte de la población. Es necesario ir más allá y desde el ámbito de la seguridad pública analizar el pro-

15 Índice de paz en México 2016, http://www.visionofhumanity. org/sites/default/files/\%C3\%8Dndice $\% 20$ de $\% 20$ Paz $\% 20 \mathrm{M} \%$ C3\%A9xico\%202016_ES.pdf blema como parte de la salud pública asociado con la generación de riqueza de la región.

Las propuestas más pertinentes para su estudio se vinculan directamente a los procesos organizativos de la sociedad civil. Los avances alcanzados por diversas organizaciones, como Alto al Secuestro, el Movimiento por la Paz con Justicia y Dignidad, la evaluación de las políticas en materia de seguridad por INCIDE Social, así como la documentación en favor de la transparencia y la defensa de los derechos humanos, se muestran como la mejor ruta.

En Guerrero existen instituciones organizativas importantes como la Coordinadora Regional de Autoridades Comunitarias (CRAC), el cual imparte justicia desde hace veinte años. De igual manera, hace cuatro años se formaron la Unión de Pueblos y Organizaciones del Estado de Guerrero y algunos Grupos de Autodefensa que han logrado contener el problema de la violencia en ciertas regiones de la entidad; no obstante, sus intentos por funcionar en las zonas urbanas han sido infructuosos, pues su sustento es la articulación social.

Existen otras organizaciones de derechos humanos que operan lejos de Acapulco, por ejemplo, el Centro de Derechos Humanos de la Montaña Tlachinollan, mismo que ha cuestionado las acciones en materia de seguridad y ha ganado presencia al obtener justicia en casos de violaciones, incluso ha recurrido a instancias internacionales.

Pese a que en la ciudad apenas comienza a ser visible el trabajo de grupos católicos, organizaciones indígenas y colectivos culturales que están generando procesos de integración en las colonias de mayor conflictividad social, los resultados serán notorios en el largo plazo. Asimismo, la Universidad Autónoma de Guerrero tuvo una función preponderante de vinculación social en su etapa de «Universidad pueblo». Similar a la Universidad de Guadalajara, debería poner en marcha un Programa para Atender a Víctimas (PAV) en el acompañamiento y 
Fotografía: Víctor Hugo Robles Mújica asesoramiento, y a miembros de la comunidad estudiantil víctimas de delitos de alto impacto. Además, debería discutir y documentar los procesos de violencia, las afectaciones y la expansión de esta sociedad de riesgo.

En esencia, la universidad pública debiera alertar sobre la urgencia de atender dichos problemas que de acuerdo con la experiencia colombiana, ${ }^{16}$ al no tener respuesta, propician pérdida de los valores, alto y episódico consumo de bebidas alcohólicas, fácil acceso al ma-

${ }^{16}$ Fernando Manuel Castro y Manuel Salazar Fierro, La respuesta a la criminalidad y la violencia en Colombia: acciones del Estado para promover la convivencia y la seguridad en las ciudades, Conferencias «Violence in Latin America: Policy Implications from Studies on the Attitudes and Costs of Violence», Cambridge, Universidad de Harvard, 19-20 de febrero de 1998. nejo de armas de fuego, mayor impunidad, baja credibilidad de las instituciones de justicia y policía, actitudes y relaciones personales que favorecen la respuesta violenta al conflicto, así como un tratamiento cada vez más inapropiado de los temas de violencia por parte de los medios de comunicación, y una presencia mayor de pandillas y grupos armados al margen de la ley.

Debería estarse construyendo un amplio movimiento que exija al Estado garantizar el derecho a la seguridad, al libre tránsito y a una vida sin violencia. Es preciso reconocer que en distintas partes del país, como ocurre en Acapulco, estamos conformando una sociedad de riesgo cuyas consecuencias serán devastadoras para la población en general.

\section{Debería estarse construyendo un amplio movimiento que exija al Estado garantizar el derecho a la seguridad, al libre tránsito}

y a una vida sin violencia.

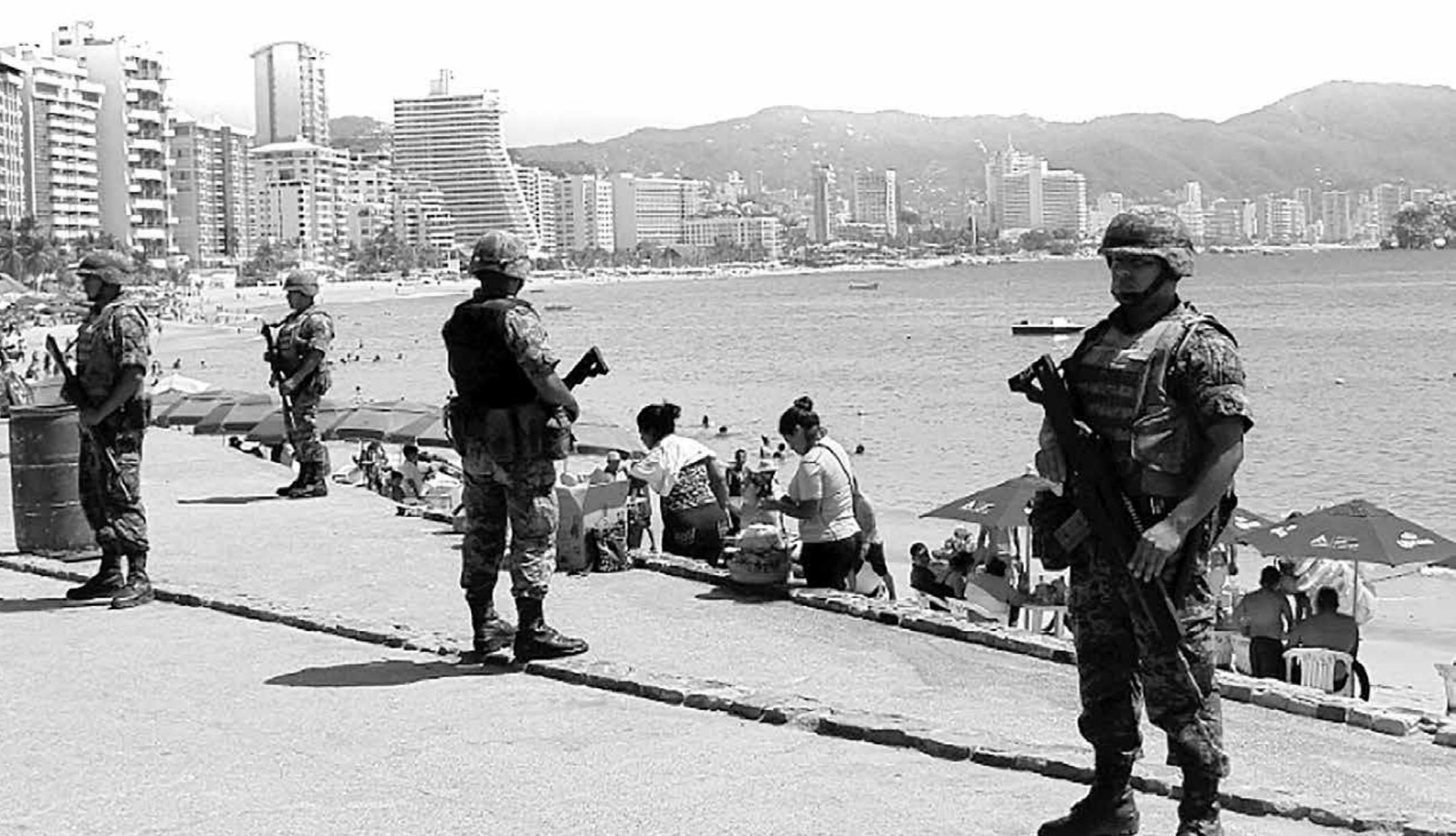

